\title{
Government Competition, Transportation Infrastructure Construction and Industrial Agglomeration
}

\author{
Yanru Deng ${ }^{1} \&$ Yixin Wang ${ }^{2}$ \\ ${ }^{1}$ School of Economics, Dongbei University of Finance and Economics, Dalian, China \\ ${ }^{2}$ School of Mathematics, University of Birmingham, Birmingham, United Kingdom \\ Correspondence: Yanru Deng, School of Economics, Dongbei University of Finance And Economics, Dalian 116000 , \\ China
}

Received: December 3, 2020 Accepted: December 27, $2020 \quad$ Online Published: January 11, 2021

doi:10.5430/jbar.v10n1p1

URL: https://doi.org/10.5430/jbar.v10n1p1

\begin{abstract}
This paper uses the prefecture-level data from 2003 to 2016 of the Yangtze River Delta region of China and uses the spatial Dubin model(SDM) to study the promotion effect of transportation infrastructure on industrial agglomeration and the spatial spillover effect: First, it is found that there is a significant positive spatial correlation between transportation infrastructure development at the prefecture and city level governments in China, which supports the hypothesis of intergovernmental transport infrastructure competition in this paper; secondly, the regression of the spatial measurement model proves that transportation infrastructure has a certain role in promoting regional industrial agglomeration, and enhances the level of industrial agglomeration in the surrounding areas through spatial spillover effects; in addition, this article uses the Spatial Dubin Model(SDM)) partial differential decomposition method to explore the spatial spillover effects of transportation infrastructure on the flow of elements (this paper explores the spatial spillover effects of transport infrastructure on factor mobility using a partial differential decomposition of the Spatial Durbin Model(SDM)); finally, the robustness of the results of this paper is tested using the replacement space weight matrix and estimation method.
\end{abstract}

Keywords: transportation infrastructure, industrial agglomeration, spatial spillover effects

\section{Introduction}

As the foundation of the national economy, transportation infrastructure plays a vital role in maintaining people's production and life and promoting economic development. There is an important practical and theoretical background for studying the role of transportation infrastructure in promoting economic activities. Over the past 30 years of China's reform and opening up, GDP has maintained rapid growth. This article selects the Yangtze River Delta City Group, one of China's three major urban agglomerations, as the research object. The Yangtze River Delta region contains a wider area than other urban agglomerations in China. The level of urban economic development in the region is quite different, and each city belongs to different cultural regions, so the study of the Yangtze River Delta region has a stronger representativeness. After more than 30 years of development, the Yangtze River Delta has formed a large industrial scale and a unique industrial system. According to the latest data, the Yangtze River Delta's GDP reached 21147.92 billion yuan in 2019, accounting for 23\% of the country's total (Note 1). However, there are certain differences in the economic development of the various regions in the Yangtze River Delta. In order to promote the coordinated development of the cities in the Yangtze River Delta, the cities in the Yangtze River Delta have increased their investment in transportation infrastructure in the region. Different from general infrastructure, transportation infrastructure has strong cross-regional network and externality. Therefore, transportation infrastructure is not only a bridge connecting all parts of society, but also a link to promote the flow of commodities. Theoretically, it is believed that on the one hand, transportation infrastructure can shorten the distance between time and space, reduce transportation costs for residents and enterprises, accelerate the flow of goods and factors, increase trade exchanges, and promote local economic growth; on the other hand, because transportation infrastructure is networked and The characteristics of externalities, coupled with the dependence of some industries on spatial regions, make the transportation infrastructure of a region not only affect the local economy, but also affect other regions connected by the transportation infrastructure, that is, a spatial spillover effect. Positive spatial spillovers can reduce trade costs between regions, form inter-regional industrial diffusion and agglomeration effects, which are conducive 
to promoting regional integration and drive the coordinated economic development of surrounding regions; negative spatial spillovers may increase underdeveloped regions The possibility and convenience of the outflow of production factors will widen the regional economic gap, which is not conducive to the coordinated development of the regional economy. However, most of the current domestic and foreign studies have reached inconsistent conclusions on the debate about whether the transportation infrastructure has positive or negative spillover to regional economic development.

With the completion of the transportation network, the reduction of transportation costs and time costs has greatly increased the market efficiency. Therefore, areas with good access to transportation have greater market potential and urban competitiveness by attracting enterprises to enter, which facilitates the industrial agglomeration. Investment in transportation infrastructure construction itself is a capital input element, Increasing on this investment is conducive to economic development. In addition, the construction of transportation infrastructure reduces transportation costs and facilitates the exchange of products and elements between regions, thereby attracting some companies to invest locally and promoting the agglomeration of elements in the local area. However, excessive investment in infrastructure construction occupies other element inputs. Which has an opposite effect on local economic growth. Due to the existence of spatial spillover effects, local transportation infrastructure construction may not be able to attract a large number of enterprises and factors to carry out a large number of production activities. Studies have shown that convenient transportation may also make the factors of backward regions be used by developed regions, thus increasing the differences between regions and reducing the degree of industrial concentration. This article discusses the impact of the construction and improvement of transportation infrastructure on the regional industrial agglomeration, studies the relationship between the two from the perspective of spatial spillover. This can comprehensively reflect the mechanism of the improvement of transportation infrastructure on the industrial agglomeration and provide some practical reference for the government to formulate regional transportation policy.

\section{Literature Review}

In recent years, investment in China's transportation infrastructure construction has increased rapidly, and traffic conditions in various regions have greatly improved. A large number of documents have analyzed the reasons for the rapid improvement of China's transportation infrastructure network from different perspectives. Most literature believes that political factors play an important role in the supply of transportation infrastructure: some scholars have studied the decision-making behavior of infrastructure distribution in different regions from the perspective of government elections (Crain \& Oakley, 1995). Rauch (1994) used US data to study how different official appointment systems impact on the infrastructure in various regions. In the current context of industrial relocation in China, governments at all levels have quickly attracted a large number of companies to carry out production activities in the local area through investment promotion. Although local government-led construction has rapidly promoted the process of agglomeration, it is not very good. Because it has limited the development of agglomeration economy because it fails to take into account the linkages between industries (Shen \& Xiang, 2017). Since the establishment of local "fiscal decentralization" and "official promotion" systems, China's transportation infrastructure has developed rapidly. However, local governments have launched fierce competition in the construction of transportation infrastructure for economic and political performance and other purposes, making the spatial distribution of transportation infrastructure also present a spatial situation of "gathering".

The literature believes that the construction of transportation infrastructure can reduce the flow cost of products and elements and promote more reasonable inter-regional allocation of elements. Improving regional production efficiency, which is conducive to regional economic development. Since the 1990s, a large number of new economic geographers have constructed models of agglomeration and dispersion to explain the influence mechanism of economic resources on the spatial distribution (Fujita, 2005). Compared with other infrastructures, the transportation infrastructure connects various regions because of its unique network nature, thereby promoting competition and cooperation between interconnected manufacturers. Because the transportation infrastructure is networked, factors and products can flow freely between regions, which can form a spatial diffusion effect of production activities. Therefore, transportation infrastructure can not only affect local economic activities, but also affect neighboring areas through spatial spillovers (Banister \& Berechman, 2000). In recent years, scholars have carried out extensive researches on the spatial spillover effects of transportation infrastructure. Most literature believes that transportation infrastructure reduces the transportation costs of local enterprises and in the mean time the externality and network nature of transportation infrastructure can also bring cross-regional impacts on economic activities in surrounding areas. Goodchild (1992) believes that spatial dependence and spatial autocorrelation are attributes of most spatial data. Closer elements interact more frequently with each other due to lower transportation costs and more frequent interactions, so that areas in closer proximity have greater mutual influence with each other. Conversely, interactions 
between more distant regions is relatively weak. The "First Law of Geography" proposed by Tobler (1979) states: "Any two are correlated, but the closer one has a strong correlation, while the far one is weaker." Ozbay et al. (2007) used data from the New York and New Jersey metropolitan areas to prove that spatial spillover effects decrease with distance (increasing distance).

By combing (combing through) the existing literature, it is found that domestic and foreign studies generally believe that the political system has an important impact on the supply of inter-regional transportation infrastructure, and existing studies generally believe that the current intergovernmental competition triggered by the tax sharing system and the official promotion system in China has promoted provision of transportation infrastructure. Existing research shows that the improvement of the transportation infrastructure network can reduce the flow cost of factors and products, and at the same time can speed up the flow of factors and products between regions. It has a spatial spillover effect, that is, the construction of transportation infrastructure can not only affect local economic activities, but also affect economic activities in neighboring areas. However, whether the spatial spillover effect of transportation infrastructure is positive or negative, that is, whether the local transportation infrastructure can promote the development of the surrounding economy or restrain the economic activities of the surrounding areas, the existing literature has great disagreements. This paper analyzes the different role of transportation infrastructure for different regions from a spatial perspective, and analyzes the spatial spillover mechanism between the "central" and "peripheral" regions. It is believed that the reason why the excessive construction of transportation infrastructure in the "central" area cannot continue to promote industrial agglomeration in the region is not because the construction of transportation infrastructure has a restraining effect on industrial agglomeration, but that with the improvement of transport infrastructure in the "peripheral" region, the attractiveness of the "peripheral" region for enterprises and factors gradually increases. The "peripheral" area has gradually become more attractive to enterprises and factors; at the same time, since the transportation infrastructure of the "central" area itself has been highly developed, it is no longer possible to enhance its attractiveness to the factors by building transportation infrastructure, making the transportation infrastructure of "central" regions show a phenomenon of "inhibition" to industrial agglomeration.

\section{Impact Mechanism Analysis and Research Hypotheses}

\subsection{Gathering Power}

In the actual production process, a series of transportation is required after the raw materials are processed into products before they can be finally delivered to consumers. Therefore, the manufacturing industry has a strong spatial dependence on the target market. The location of manufacturing companies is usually close to the origin of raw materials or the consumer market. On the one hand, it can reduce the transportation cost of the product, on the other hand, it can also increase the delivery speed and reduce the transportation risk. However, the improvement of transportation infrastructure has greatly reduced transportation costs and increased transportation speed, thus breaking the original spatial pattern. Baldwin et al. (2011) believe that public infrastructure reduces the transportation cost of products, thereby reducing the price of various products in the region, which increases demand in the region and attracts enterprises from outside the region to move in. Lanaspa et al. (2001) found that under the same other conditions, companies would choose to cluster in areas with better transportation infrastructure. The location choice of manufacturing companies is affected by both transportation infrastructure and market access. Transportation infrastructure has an impact on the development of manufacturing by reducing the "natural barriers" between regions (Liu \& Zhao, 2010). New Economic Geography believes that when making Location selection decisions, companies pay more attention to the forward and backward relationships with upstream and downstream manufacturers. Under the conditions of increasing transportation costs and Scale returns, closer forward and backward connections can reduce the transportation costs of buying intermediate goods and selling products, thereby attracting a large number of enterprises to settle in (Jin \& Tokunaga, 2010).

Marshall uses the "labor pool" theory to explain the phenomenon of agglomeration: enterprises in the agglomeration area compete with enterprises outside the area when recruiting labor. Because the enterprises in the area have production advantages over those outside the area, they can pay higher wages. In terms of labor mobility, the labor force flows into the zone driven by higher wages, forming a labor pool. Due to the large amount of labor are gathered in the region, enterprises in the region can quickly hire labor to fill the corresponding job vacancies, thereby improving the efficiency of matching labor elements and positions (Liu \& Wen, 2015)

Finally, Marshall pioneered the theory of knowledge spillover, which is believed that knowledge spreads through spillover. Knowledge is divided into explicit knowledge and tacit knowledge. Explicit knowledge is codifiable knowledge and is usually transmitted through media such as language and writing, while tacit knowledge usually 
cannot be spread through language and writing. It is a practical experience type of knowledge, which needs to be learned through face-to-face communication and long-term interaction. As a result, the cost of tacit knowledge transmission increases with the increase of distance. Therefore, the geographical concentration of economic activities is conducive to the overflow of tacit knowledge.

\subsection{The Role of Transportation Infrastructure}

New economic geography believes that the layout of economic activities is determined by the balance of regional "centripetal force" and "centrifugal force".Due to the influence of natural, social, historical and other factors, the flow of economic activities between regions is not completely without resistance(free of resistance). And the flow of elements in space is "sticky." As a lubricant for the flow of products and factors, transportation infrastructure can reduce the resistance of non-economic factors to the flow of economic factors. The difference in the distribution of transportation infrastructure between regions will have an important impact on the balance of regional "centripetal force" and "centrifugal force".

\subsubsection{Reduce Logistics Costs}

The ordering process of raw materials and intermediate products includes the process of transportation and inventory management, not just the transportation of goods. The inventory cost of an enterprise includes the inventory holding cost and inventory acquisition cost of the enterprise. Inventory holding cost refers to the cost of the enterprise in inventory management, and the inventory acquisition cost is the transportation cost of the goods. And to study the impact of transportation infrastructure on the inventory cost of enterprises while examining the reduction of goods transportation costs and the improvement of transportation efficiency, so the study of transportation infrastructure construction on the reduction of enterprise inventory costs can be a good study when the transportation infrastructure is improved. Decision-making behavior.

When making inventory decisions, companies must consider both the acquisition cost of inventory and the holding cost of inventory. The currently widely used $(\mathrm{S}, \mathrm{s})$ inventory model believes that when the company's productivity is constant, the company's inventory level will decrease when the company's production progresses, and as the company's inventory level decreases, the inventory holding costs will also gradually decreases. When the inventory level drops below the level that can ensure the continuity of production (that is, the safety stock level s), the company needs to replenish the inventory and make the inventory level reach the target level S. Since it takes a certain amount of time for the company to order raw materials and intermediate products to the supplier to transport the raw materials and intermediate products to the company, the company should place an order for inventory before the inventory is exhausted to ensure the continuation of production. Ideally, the company's inventory is depleted between the time an order is placed and the time the raw materials are put into storage. This period of time is called the lead time and is represented by $t$. The above analysis is represented by the following figure:

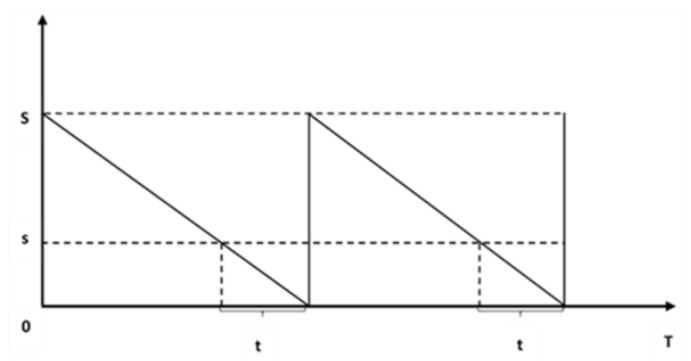

Figure 1. (S,s) inventory model

The quantity Q of the inventory ordered by the enterprise depends on the initial inventory level $\mathrm{N}$ and the current consumption inventory level $\mathrm{x}$ :

$$
\mathrm{Q}=\left\{\begin{array}{lll}
S-s & \text { if } & N-x<s \\
0 & \text { if } & N-x>s
\end{array}\right.
$$

Based on the production goal of minimizing cost, companies will make a decision between reducing inventory acquisition costs and reducing inventory holding costs to reduce inventory costs. When an enterprise lowers the 
target inventory level to reduce inventory holding costs, frequent logistics and transportation also increase the cost of acquiring enterprise inventory. A comprehensive transportation infrastructure network makes the inventory transportation process of the enterprise faster and more reliable, so it can significantly Reduce lead time, companies no longer have to hold too much inventory. In order to reduce inventory holding costs, companies will choose to reduce the company's target inventory level S. Therefore, convenient transportation conditions reduce the cost of inventory acquisition while reducing inventory holding costs. Therefore, strengthening the construction of transportation infrastructure can effectively reduce inventory costs for companies. Shirley and Winston (2004) used data on US highway inventory and corporate inventory levels to confirm that transportation infrastructure can reduce corporate inventory costs.

\subsubsection{Reduce Factor Flow Costs}

The development of transportation infrastructure can reduce the flow cost of factors and products, and promote the deepening of the economic division of labor between regions. The agglomeration economy that can be produced by industrial agglomeration allows enterprises and factors to flow to the regions that are suiTable for it. Because different regions have different location conditions and corresponding advantageous industries, the construction of transportation infrastructure can promote regional specialized agglomeration. The improvement of transportation infrastructure has increased the frequency and quantity of the exchange of goods between regions, and different regions have their own comparative advantages due to geographical, historical, cultural and other factors. The improvement of transportation infrastructure can strengthen the specialized division of labor between regions and improve production efficiency (Huang \& Li, 2006).

When choosing a job, labor forces tend to consider issues such as supporting parents and Enrolment of children. Therefore, the social nature of the labor force makes the spatial mobility of the labor force "sticky", making the labor force often choose to work in places close to home, which is not conducive to the distance from the central city. Geographic concentration of elements in remote areas. With the improvement of the transportation infrastructure network, the flow cost of labor elements has decreased, which has promoted the inflow of labor elements to areas with greater labor demand, and the spatial agglomeration of a large number of labor elements is conducive to the overflow of tacit knowledge.

\subsubsection{Industrial Diffusion Theory}

Industrial agglomeration formed in a specific location can reduce the production cost of local enterprises and enhance the competitiveness of enterprises. The rich upstream and downstream enterprises in the industrial agglomeration area and frequent commodity transportation enable enterprises to greatly reduce the transportation cost of products. With the formation of regional advantages, good regional production conditions will attract more companies. However, this trend of continuous agglomeration will not last forever. With the continuous increase of regional economic activities, problems such as rising land prices, increasing product and element competition, and environmental pollution will gradually appear in the agglomeration area. These factors constitute the "centrifugal force" of the region, produce a "congestion effect", hinder the further agglomeration of industries in the region, and promote the gradual diffusion of industries to the periphery.

The construction and improvement of transportation infrastructure can reduce the transportation cost of products, personnel and knowledge, and the power of agglomeration comes from the reduction of transportation costs in the flow of spatial elements. In addition, the connection of transportation infrastructure has a spatial spillover effect on the spatial flow of elements. Therefore, transportation infrastructure can not only promote economic activities in the region, but also promote or inhibit the development of surrounding areas through inter-industry linkages. The inter-transportation network allows elements to flow more conveniently into the surrounding areas with more advantages. Whether the spatial spillover effect of transportation infrastructure is positive or negative depends on the balance of centrifugal force and centrifugal force in each region. Based on the above analysis, the following hypotheses are proposed:

Hypothesis 1: There is a "competitive effect" in the local government's transportation infrastructure decision-making. From a spatial perspective, the construction of transportation infrastructure presents a situation of spatial agglomeration.

The promotion of local officials in China is determined by measuring their political performance during their tenure. Therefore, local officials in China have an incentive to build more transportation infrastructure. Horizontal competition among local governments has increased the construction of transportation infrastructure. Under the incentive of promotion, local officials will take various measures to promote regional economic growth, and the 
construction of a large number of transportation infrastructure is an effective way. The development of decentralization theory has led scholars to recognize that the use of a decentralized approach to infrastructure provision can facilitate the provision of more transportation infrastructure by governments (Zhou et al., 2013).

After the reform of the tax-sharing system, the tax authority of the Chinese central government is delegated to local governments to a certain extent. Although local governments cannot decide on the types of taxes and set tax rates, they can take a series of measures to optimize the regional investment environment to enhance their own attractiveness to production factors. In addition, the system of promotion of local officials in China has led to competition among local governments for transportation infrastructure in order to attract more investment and labor, often to provide better travel conditions for businesses and residents. Since the promotion of local officials has been linked to the development of the local economy since the 1980s, local government officials have launched a "promotion tournament" to promote the regional economy (Zhou, 2004). With the increasing development of China's economy, local governments are paying more and more attention to the role of enterprises in ensuring employment and promoting regional development. Transportation infrastructure can reduce enterprise costs and connect enterprise production and sales. Therefore, a good transportation infrastructure is the key to attracting companies to choose locations. In order to compete for resources, attract the rapid inflow of capital, and promote local economic development to improve the performance of officials in governance, competition among local governments for factors such as labor and capital has become increasingly fierce. For a long time, the advantageous areas have undergone continuous development, both in terms of transportation infrastructure and economic construction, with a relatively high degree of development. However, government officials in neighboring areas face greater promotion pressure under the existing promotion system. Therefore, in order to improve the business and living environment of the region, government officials in the surrounding areas will also increase the construction of transportation infrastructure in the region, thus presenting the status of spatial agglomeration in the construction of regional transportation infrastructure. Based on the intergovernmental competition theory, hypothesis 2 is proposed.

Hypothesis 2: The impact of transportation infrastructure on industrial agglomeration has obvious spatial spillover effects.

\section{Empirical Results and Analysis}

\subsection{Data Processing}

\subsubsection{Data Source and Processing}

The existing research on transportation infrastructure mostly selects provincial panel data for the agglomeration economy literature. However, the provincial panel data has a large scale, and the gap between cities in the province is generally large, and it is difficult to capture spatial overflow. Compared with the use of national provincial panel data, selecting research objects in a specific area is more targeted. And this article focuses on the promotion of competition between local governments on the construction of transportation infrastructure in different regions, and thus the impact on the flow of factors. The use of data from prefecture-level cities is more in line with the purpose of this article. In addition, the existing literature finds that the centralized supply of policies is not necessarily caused by intergovernmental competition, but may also be caused by regional policies. China's regional policies usually focus on promoting the Yangtze River Delta, the Pearl River Delta, and the Beijing-Tianjin-Hebei region. The development of transportation infrastructure in these areas is not necessarily caused by inter-governmental competition from a national perspective. The use of prefecture-level panel data in the Yangtze River Delta region can better illustrate that inter-governmental competition makes transportation infrastructure. The facilities present a concentrated supply. Therefore, this paper selects the city-level panel data in the Yangtze River Delta for regression analysis.

The data used in this article are mainly derived from the "China City Statistical Yearbook" and "China Statistical Yearbook". Since the "China City Statistical Yearbook" has changed the industry statistics since 2003, the original 15 industries have been expanded to 19 industries, so this paper selects data of 40 cities in the Yangtze River Delta region from 2003 to 2016 for a total of 14 years (because Chaohu City in Anhui Province cancelled prefecture-level cities in 2011 and established county-level Chaohu City. Zhoushan City, Zhejiang Province is an archipelago-based city, Other cities are not connected by land, so this paper selects data other than Chaohu and Zhoushan). Before the empirical analysis, this article has carried out logarithmic processing of variables to eliminate certain heteroscedasticity problems and dimensional inconsistencies. In order to eliminate the influence of price factors, the nominal variables in this paper are adjusted to actual values through the GDP conversion index (using 2003 as the base period). 


\subsubsection{Variable Description}

\section{(1) The explained variable}

In the existing literature, two methods are usually used to measure industrial agglomeration. One type of index focuses on measuring the degree of regional specialization (that is, compared with the national average, the output value, employment, or output of the study area is more concentrated in Which industry). Such indicators usually include Krugman Index (Huang \& Li, 2006), location entropy and other indicators. Another type of index focuses on measuring the intensity of factors and output value in space. Zhang \& Wang (2014) respectively used employment density (employed population divided by urban area) and output per unit area to measure industrial agglomeration. This measure of the spatial density of factors or output is a better measure of the spatial concentration of economic activity in a region. Since the output value of various products is affected by factors such as production efficiency, areas with low factor density may also have higher output value due to higher productivity, which will bias the measurement of agglomeration density. Therefore, this article draws on Fan (2006) The employment density is used to measure the degree of agglomeration.

\section{(2) Explaining variables}

In the existing literature on transportation infrastructure, there are some literatures that regard transportation infrastructure as an investment, and use currency to measure the construction of transportation infrastructure in a certain area (Aschauer, 1989); another type of literature uses The density of transportation lines (such as roads, railways, inland waterways, etc.) to measure the construction status of regional transportation infrastructure (Zhang Xueliang, 2012). Taking the form of currency to measure transportation infrastructure will be affected by the difficulty of construction, local prices and personnel wages. For example, the difficulty of construction of transportation infrastructure in mountainous and plateau areas is generally higher than that in plain areas, so the cost of transportation infrastructure in mountainous areas is generally higher. And from a micro perspective, the investment in transportation infrastructure does not affect the company's location decision. When making location decisions, companies usually consider the difficulty of obtaining raw materials and selling products in the region. Companies usually tend to be located in areas with high traffic infrastructure density and high accessibility. Therefore, this paper chooses highway density (road mileage/urban land area) to measure the construction status of transportation infrastructure.

(3) Control variables

Combining existing literature, this article selects local protectionism, city size, human capital, service industry development, and opening to the outside world as control variables (Shi \& He, 2011). Local governments often have a tendency to raise the barriers to entry for businesses from other regions for, among other reasons, higher taxes, thereby ensuring that local businesses benefit. Young (2000) believes that the barriers set up by local governments make it impossible for local commodities to circulate freely across regions, thereby reducing the specialized division of labor between regions and making the industrial structure of different regions converge. Therefore, it is necessary to consider local protection factors when discussing the division of labor between regions. However, compared with tariff barriers in international trade, local protectionism has characteristics that are difficult to measure. In order to sell more products, companies tend to locate in areas with a larger market for production and sales activities. Different city scales will have different effects on industrial agglomeration. This article uses the actual GDP of each city to measure the city scale. Knowledge spillovers are divided into "explicit knowledge spillovers" and "tacit knowledge spillovers". "Explicit knowledge" is knowledge that can be expressed, usually using language and writing as a medium, and can be spread over long distances. "Tacit knowledge" cannot be expressed through words, and usually needs to be obtained through long-term collaboration between people, so "tacit knowledge spillover" is more regional. Therefore, the high concentration of talents has significantly promoted knowledge spillover, especially the spillover effect of "tacit knowledge" can promote the improvement of regional specialization agglomeration. Education is the source of human capital. This article uses the ratio of university teachers in each city to the city's average level to measure the basic human resources. The service industry is usually concentrated in larger cities and promotes the diversified agglomeration of the region through its promotion of manufacturing. This article uses the added value of the tertiary industry as a percentage of GDP to measure the development of the service industry. The demonstration effect and the attraction of the learning effect make a large number of companies gather around multinational companies. This article uses the ratio of each city's FDI to the national average level to measure the openness of the study area. The descriptive statistical results of this article are as follows: 
Table 1. Descriptive statistics of variables

\begin{tabular}{llllll}
\hline variables & mean & sd & min & p50 & max \\
\hline lnjymd & 0.0092 & 0.0124 & 0.0007 & 0.0061 & 0.1082 \\
lnglmd & 0.0753 & 0.4373 & -1.3584 & 0.1641 & 1.4129 \\
lnrgdp & 16.0707 & 1.0335 & 13.5345 & 16.0161 & 18.9520 \\
lndfbh & 0.0766 & 0.0268 & 0.0214 & 0.0743 & 0.2048 \\
lnrlzb & 0.5312 & 0.5079 & 0.0212 & 0.3763 & 2.2720 \\
lnfwy & 3.6469 & 0.1711 & 3.1510 & 3.6424 & 4.2453 \\
lnfdi & 10.7585 & 1.6086 & 6.2804 & 10.8918 & 14.4314 \\
\hline
\end{tabular}

\subsection{Spatial Correlation Test}

\subsubsection{Spatial Weight Matrix}

The spatial weight matrix can measure the strength of regional economic ties by assigning values to the economic ties between different regions. The important difference between spatial measurement and traditional measurement is that spatial measurement introduces a spatial weight matrix, which can be based on specific research purposes. To set the corresponding spatial weight matrix (Bavaud, 2013). The form of the spatial weight matrix $\mathrm{W}$ is as follows:

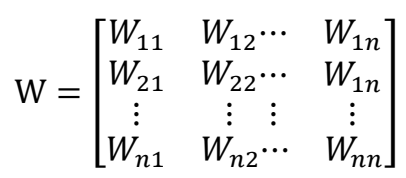

$\mathrm{Wij}$ in the spatial weight matrix measures the strength of the economic connection between regions $\mathrm{i}$ and $\mathrm{j}$, and specifies that the distance between a region and itself is 0 , so the elements $\mathrm{W}_{11}, \mathrm{~W}_{22}, \mathrm{~W}_{33} \ldots \mathrm{Wnn}$ on the main diagonal are all 0 . The spatial weight matrix can be set to different values according to $\mathrm{W}_{\mathrm{ij}}$, and it can be divided into a spatial adjacency weight matrix, an inverse distance weight matrix, and a nested matrix.

(1) Spatial adjacency weight matrix

The adjacency weight matrix is divided into first-order adjacency and high-order adjacency. The first-order adjacency matrix (First Order Contiguity Matrix) is also called binary adjacency matrix or 0-1 matrix. It only considers the spatial dependence between two directly adjacent regions. The high-order adjacency matrix not only considers the spatial effects between directly adjacent regions, but also includes spatial spillovers in a larger range caused by transmission. The existing research generally uses the first-order adjacency matrix in the form:

$$
W_{i j}=\left\{\begin{array}{lr}
0 & , \text { Regions } \mathrm{i} \text { and } \mathrm{j} \text { are not adjacent to each other or } \mathrm{i}=\mathrm{j} \\
1 & , \text { Have a common boundary between regions } \mathrm{i} \text { and } \mathrm{j}
\end{array}\right.
$$

The adjacency matrix has the advantages of convenient setting and easy calculation, but the adjacency matrix can only be used to study the geographic space defined by the adjacent relationship, and cannot be used to measure the inter-regional relationship established due to geographic distance and social and economic relations between regions. Therefore, researchers incorporate geographic distance and social factors into the spatial weight matrix, which can overcome the shortcomings of the adjacency weight matrix to some extent.

(2) Geographic distance weight matrix

The inverse distance weight matrix sets the weight matrix by the distance dij between area $i$ and area $\mathrm{j}$. It is assumed that the relationship between areas decreases as the distance between areas increases. The general form is:

$$
W_{i j}= \begin{cases}d_{i j}^{-a} \beta_{i j}^{b} & , \text { when } i \neq j \\ 0 & , \text { when } i=j\end{cases}
$$

Among them, $\mathrm{b}$ is the boundary sharing effect coefficient. Researchers believe that inter-regional connections are not only related to dij, but also affected by the length of the shared boundary between regions. However, in most studies, $\mathrm{b}$ is set to 0 and $\mathrm{a}$ is set to 2 . The specific form is: 


$$
W_{i j}= \begin{cases}\frac{1}{d_{i j}^{2}} & , i \neq j \\ 0 & , i=j\end{cases}
$$

It is the geographic distance matrix.

\section{(3) Nested matrix}

The setting of the nested weight matrix for Wij considers both distance factors and social

factors, which can reflect complex spatial effects more comprehensively. This article refers to Wang Huogen and Shen Lisheng (2007) using the product of the geographical distance matrix $\mathrm{w}$ and the diagonal matrix whose average proportion of GDP per capita in each region is diagonal to obtain the nested matrix W.

$$
\mathrm{W}_{i j}=\mathrm{w} * \operatorname{diag}\left(\frac{\overline{y_{1}}}{\bar{y}}, \frac{\overline{y_{2}}}{\bar{y}}, \cdots, \frac{\overline{y_{n}}}{\bar{y}}\right)
$$

Among them $\overline{y_{i}}=\frac{1}{t_{1}-t_{0}+1} \sum_{t_{0}}^{t_{1}} y_{i t}$

$$
\bar{y}=\frac{1}{n\left(t_{1}-t_{0}+1\right)_{i=1}} \sum_{i=1}^{n} \sum_{t_{0}}^{t_{1}} y_{i t}
$$

By constructing these three spatial weight matrices at the same time, it is possible to avoid biased estimation results caused by a single matrix setting, and to pave the way for the following spatial measurement regression process by comparing different weight matrices. There is a deeper relationship between transportation infrastructure and industrial agglomeration.

\subsubsection{Global Spatial Autocorrelation}

Although there are significant differences in economic activity between regions, the degree of industrial agglomeration in various regions may be spatially related. The construction of facilities will not only affect the agglomeration of industries in the region, but also the agglomeration of industries in neighboring regions. When there is a spatial correlation between economic variables, that is, when a change in a certain economic variable in the region has a certain impact on the surrounding area, ordinary panel measurement methods cannot be used to estimate, and regionally related economic variables should be evaluated. For estimation, we must first test whether there is a spatial correlation between the regional variables.

The test of spatial autocorrelation can usually be measured by Moran's I, Geary's C and other indices. At present, scholars use Moran index to test the spatial autocorrelation of spatial elements. Benefits of taking Moran Index:

Moran's I index is divided into global Moran's index and local Moran's index. The global Moran's I index can be used to determine the "statement" of a spatial variable as a whole. The formula for calculating Moran's I Index is as follows:

$$
\text { Moran's I } \frac{\sum_{i=1}^{n} \sum_{j=1}^{n} W_{i j}\left(X_{i}-\bar{X}\right)\left(X_{j}-\bar{X}\right)}{S^{2} \sum_{i=1}^{n} \sum_{i=1}^{n} W_{i j}}
$$

Among them, $x_{i}, x_{j}$ represent the observed values of city $i$ and $j$ respectively; $n$ represents the number of research areas; Wij represents the spatial weight matrix; $\mathrm{X}$ is the sample mean; in addition, is the sample variance, the formula is:

$$
S^{2}=\frac{1}{n} \sum_{i=1}^{n}\left(X_{i}-\bar{X}\right)^{2}
$$

The spatial "state" usually has three forms: spatial agglomeration, spatial diffusion and spatial randomness. Spatial measurement usually studies the agglomeration and diffusion of elements in space. When the Moran's I index is greater than 0, the spatial elements present an agglomeration state; if the Moran's I index is less than 0, the spatial elements present a diffusion state. Moran's I index generally takes a value between [-1,1]. The closer the value of Moran's I index is to 1, the more spatial agglomeration of neighboring regions is; the Closer it is to -1 , the more differentiated the distribution of economic activity in neighboring areas. When the Moran index is not significant, there is no obvious trend of agglomeration or diffusion of the elements, that is, the space is random. Whether to add spatial effects to the model depends on whether each variable has the characteristics of spatial autocorrelation. This 
paper uses the global Moran index to test whether each variable has the characteristics of spatial autocorrelation in geographic distribution (Table 2).

Table 2. Moran's I index calculated based on the adjacency weight matrix

\begin{tabular}{|c|c|c|c|c|c|c|}
\hline \multirow{2}{*}{ years } & \multicolumn{2}{|c|}{ Adjacency matrix } & \multicolumn{2}{|c|}{ Inverse distance matrix } & \multicolumn{2}{|c|}{ Nested matrix } \\
\hline & lnjymd & lnglmd & lnjymd & lnglmd & lnjymd & lnglmd \\
\hline 2003 & $0.1610^{*}$ & $0.1460 *$ & $0.1060 * *$ & $0.1310 * *$ & $0.0470 * * *$ & $0.0420 * * *$ \\
\hline 2004 & $0.1950 * *$ & $0.2770 * * *$ & $0.1230 * *$ & $0.2040 * * *$ & $0.0540 * * *$ & $0.0940 * * *$ \\
\hline 2005 & $0.2250 * *$ & $0.2110 * *$ & $0.1370 * *$ & $0.1750 * * *$ & $0.0610 * * *$ & $0.0750 * * *$ \\
\hline 2006 & $0.2220 * *$ & $0.2920 * * *$ & $0.1420 * *$ & $0.2080 * * *$ & $0.0640 * * *$ & $0.0880 * * *$ \\
\hline 2007 & $0.2310 * *$ & $0.3500 * * *$ & $0.1550 * * *$ & $0.2240 * * *$ & $0.0710 * * *$ & $0.0980 * * *$ \\
\hline 2008 & $0.2320 * *$ & $0.3870 * * *$ & $0.1640 * * *$ & $0.2440 * * *$ & $0.0740 * * *$ & $0.1100 * * *$ \\
\hline 2009 & $0.2210 * *$ & $0.3690 * * *$ & $0.1550 * * *$ & $0.2380 * * *$ & $0.0690 * * *$ & $0.1070 * * *$ \\
\hline 2010 & $0.2250 * *$ & $0.3970 * * *$ & $0.1620 * * *$ & $0.2610 * * *$ & $0.0730 * * *$ & $0.1180 * * *$ \\
\hline 2011 & $0.2840 * * *$ & $0.3930 * * *$ & $0.1980 * * *$ & $0.2540 * * *$ & $0.0830 * * *$ & $0.1160 * * *$ \\
\hline 2012 & $0.2780 * * *$ & $0.4030 * * *$ & $0.1860 * * *$ & $0.2670 * * *$ & $0.0780 * * *$ & $0.1160 * * *$ \\
\hline 2013 & $0.2970 * * *$ & $0.4000 * * *$ & $0.2210 * * *$ & $0.2490 * * *$ & $0.1010 * * *$ & $0.1120 * * *$ \\
\hline 2014 & $0.2890 * * *$ & $0.4020 * * *$ & $0.2150 * * *$ & $0.2650 * * *$ & $0.1000 * * *$ & $0.1260 * * *$ \\
\hline 2015 & $0.2970 * * *$ & $0.4040 * * *$ & $0.2180 * * *$ & $0.2510 * * *$ & $0.0910 * * *$ & $0.1200 * * *$ \\
\hline 2016 & $0.2990 * * *$ & $0.2320 * * *$ & $0.2180 * * *$ & $0.1030 * * *$ & $0.0920 * * *$ & $0.0460 * * *$ \\
\hline
\end{tabular}

Note. The superscripts *,**,*** represent the significance levels of $10 \%, 5 \%$, and $1 \%$ respectively, and the same below.

It can be seen from the specific Moran's I index that the lnjymd and lnglmd variables are significantly positive in the global Moran index based on the three spatial weight matrices in most years, indicating that the variables have a very obvious spatial spillover effect, that is, a certain economy in the region Variables can affect variables in neighboring areas through spatial correlation. In most years, lnjymd and lnglmd are significantly positive at the statistical level of $1 \%$ under the settings of adjacency matrix, inverse distance matrix and nested matrix, and they are all higher relevence under the settings of these three spatial weight matrices. The results of Moran's I index test show that:

(1) Both lnjymd and lnglmd have a high degree of spatial spillover effects, and the performance is positive; the result of Moran's I index test demonstrates Hypothesis 1, that is, the construction of inter-regional transportation infrastructure shows a situation of spatial agglomeration. The density of transportation infrastructure construction in the surrounding areas of cities with higher density is also higher, and the density of transportation infrastructure construction in surrounding areas of cities with lower density of transportation infrastructure construction is also lower. Therefore, the construction density of transportation infrastructure between adjacent cities has a certain competitiveness, which verifies the transportation infrastructure competition hypothesis in this article.

(2) The Moran's I index is significantly non-zero, indicating that the variables have a high degree of spatial autocorrelation. The use of spatial measurement methods can well deal with the deviation of the traditional measurement method estimation results due to the omission of spatial effects.

\subsubsection{Local Spatial Autocorrelation}

The global Moran's I index can only indicate the overall status of the agglomeration and distribution of urban transportation infrastructure and industries in the Yangtze River Delta from 2003 to 2016, but it cannot reflect the spatial agglomeration characteristics of each city and the degree of difference between cities. Therefore, the local Moran index is usually used to further investigate the distribution status of different regions reflected by the observation value and the correlation between regions. 


$$
\text { Moran's } \mathrm{I}_{i}=\left(X_{i}-\bar{X}\right) \frac{\sum_{j=1}^{n} W_{i j}\left(X_{j}-\bar{X}\right)}{S^{2}}
$$

The meaning of the local Moran index is similar to that of the global Moran index. When Moran's I is greater than zero, it means the area with high observation value is adjacent to the area with high observation value; when Moran's I is greater than zero, the area with high observation value is adjacent to the area with low observation value. Moran's I scatter plots are usually used to show the differences in the distribution of observations in various regions. The four quadrants of the coordinate system on the Moran's I scatter chart represent the four states of the observation value in the spatial distribution. This article summarizes the Moran's I scatter chart information as Table 3: Variables in the first quadrant indicate the observation value in the region is relatively high, and the observation value in the surrounding area is also relatively high, the spatial connection form is $(\mathrm{HH})$; the variable falls in the second quadrant, indicating that the observation value in this area is relatively low and the surrounding area is high (LH); the variable falls in the third quadrant shows that the area itself owns low observation value, and the surrounding area also owns low observation value (LL); the variable falling in the fourth quadrant represents the distribution of HL. This paper selects the traffic infrastructure construction and industry agglomeration data in the Yangtze River Delta in 2003 and 2016, and draws Moran scatter plots of the traffic infrastructure construction and industry agglomeration in the Yangtze River Delta respectively.

From Table 3, it can be seen that local Molan index of the traffic infrastructure construction density in the Yangtze River Delta in 2003 and 2016 is greater than 0, confirming that the traffic infrastructure is spatially clustered. Specifically, Shanghai, Suzhou, Hefei and other cities have always been in the first quadrant, indicating that these cities not only have good transportation infrastructure, but also have relatively complete transportation infrastructure in the surrounding areas. Huai'an, Hangzhou, Huzhou and other regions have always been in the third quadrant, indicating that the construction of transportation infrastructure in these areas and their neighboring areas is relatively backward.

In addition, the following Table shows that most of the 40 cities in the Yangtze River Delta selected in this article are in the first and third quadrants of the coordinate axis, and the number of cities in the first and third quadrants increased significantly in 2016, indicating that the cities have expanded firce competition in transportation infrastructure construction. For example: Jiaxing, which is closer to Shanghai, was in the second quadrant in 2003, and its spatial distribution was LH. It shows that the density of transportation infrastructure in Jiaxing is relatively low, while the construction of transportation infrastructure in the surrounding areas is relatively good. In 2016, Jiaxing moved to the first quadrant, and the spatial distribution state showed $\mathrm{HH}$, indicating that during this period, Jiaxing has strengthened the construction of local transportation infrastructure. There are also central cities that have a positive spatial spillover effects on the surrounding areas. For example, Nanjing was in the fourth quadrant in 2003 and moved to the first quadrant in 2016. At the same time, Zhenjiang and Taizhou around Nanjing moved from the second quadrant to the first quadrant, indicating that Nanjing has been relatively complete in the construction of transportation infrastructure during this period, while the surrounding areas have strengthened the construction of transportation infrastructure, indicating that Nanjing's transportation Infrastructure construction has produced a positive spatial spillover to surrounding areas.

Table 3. Local spatial autocorrelation of industrial agglomeration

Types $2003 \quad 2016$

Shanghai, Suzhou, Changzhou, Xuzhou, Shanghai, Nanjing, Suzhou, Changzhou, Xuzhou, Zhenjiang,

HH Yangzhou, Suqian, Hefei, Bengbu, Huainan, Hefei, Wuhu, Huainan, Jiaxing, Ma'anshan, Wuxi, Suzhou, Maanshan, Bozhou, Suzhou (12) Huaibei, Bengbu, Taizhou, Fuyang, Wazhou (18)

Taizhou, Zhenjiang, Huaibei, Fuyang, Jiaxing, Yangzhou, Chuzhou, Suqian, Yancheng, Anqing, Lu'an,

LH Lianyungang, Lu'an, Yancheng, Chuzhou, Yangzhou, Anqing, Xuancheng (11)

Huai'an, Hangzhou, Huzhou, Shaoxing, Huai'an, Hangzhou, Ningbo, Huzhou, Shaoxing, Jinhua, LL Taizhou, Quzhou, Wenzhou, Lishui, Chizhou, Taizhou, Lishui, Quzhou, Wenzhou, Huangshan, Xuancheng Huangshan (10) Tongling, Ningbo, Jinhua, Wuhu, Wuxi, Lianyungang, Nantong, Tongling (3)
Nantong, Nanjing (7) 
The above analysis shows that the cities in the Yangtze River Delta region selected in this article have a certain degree of inter-regional competition in the construction of transportation infrastructure. Next, we will summarize the Moran's I scatter diagram information of the industry agglomeration in the Yangtze River Delta region into Table 4 below.

It can be seen from Table 4 that in 2003 and 2016, the employment density in the Yangtze River Delta also showed a trend of spatial agglomeration. Specifically, in 2003, there were 14 cities in the first quadrant, including Shanghai, Hangzhou, Wuxi, Suzhou, etc. The spatial agglomeration state was in the form of HH, indicating that Shanghai and Hangzhou have a relatively high degree of industrial agglomeration, and the degree of industrial agglomeration in the surrounding areas is also relatively high. In the third quadrant, there are 15 cities including Lianyungang, Bengbu, Anqing, etc. The spatial agglomeration state is in the form of LL, and the areas with low agglomeration in these areas are adjacent to the low areas. The distribution status of industry agglomeration in the second and fourth quadrants is not typical (LH or HL). From the above analysis, it can be seen that the distribution of industries in the Yangtze River Delta region mainly presents a situation of spatial agglomeration. And over time, the state of industrial agglomeration in certain cities has changed. For example, in 2003, Wuhu and Ma'anshan, which had a high degree of agglomeration, had a decline in industrial agglomeration from the first quadrant to the second and third quadrants in 2016, while the agglomeration degree of Huzhou in Zhejiang increased, moved from the second quadrant to the second One quadrant.

Table 4. Local spatial autocorrelation of industrial agglomeration

\begin{tabular}{ll}
\hline Types & 2003 \\
\hline HH & $\begin{array}{l}\text { Shanghai, Wuxi, Suzhou, Changzhou, Nantong, Shanghai, Wuxi, Suzhou, Changzhou, Nantong, } \\
\text { Taizhou, Yangzhou, Zhenjiang, Hangzhou, Taizhou, Yangzhou, Zhenjiang, Hangzhou, } \\
\text { Ningbo, Jiaxing, Shaoxing, Wuhu, Ma'anshan (14) Ningbo, Jiaxing, Huzhou, Shaoxing (13) }\end{array}$ \\
\hline LH & $\begin{array}{l}\text { Yancheng, Chuzhou, Xuancheng, Ma'anshan, } \\
\text { Lishui (5) }\end{array}$ \\
\hline LL & $\begin{array}{l}\text { Lancheng, Huzhou, Chuzhou, Xuancheng (4) } \\
\text { Lishui, Quzhou, Bengbu, Suzhou, Bozhou, Bengbu, Suzhou, Huaibei, Lu'an, Fuyang, }\end{array}$ \\
\hline HL & $\begin{array}{l}\text { Fuyang, Anqing, Lu'an, Chizhou, Huangshan (15) Bozhou, Anqing, Chizhou, Huangshan (14) } \\
\text { Huaibei, Tongling (7) }\end{array}$ \\
\hline
\end{tabular}

\subsection{Empirical Results and Analysis}

Spatial measurement models can well estimate the relationship between variables with spatial effects. Commonly used spatial measurement models include spatial lag model (SLM), spatial error model (SEM) and spatial Dubin model (SDM).

The spatial lag model (SLM) is usually used to explore whether there is a spatial spillover effect of variables between regions. The spatial error model (SEM) is usually used to study whether the spatial spillover effect is realized through the spatial transmission of the error shock. Lesage \& Pace (2009) also considered the spatial dependence of the explanatory variables and the explained

variables, and constructed the Spatial Durbin model. The Spatial Dubin Model (SDM) contains both the spatial lag of the explanatory variables and the spatial lag of the explained variables. The reason for introducing the spatial lag of the independent variables and the dependent variables at the same time is that the spatial lag of the transportation infrastructure has the following mechanisms: First, most of the existing literature has confirmed the characteristics of spatial correlation between regional economic activities. Economic activities are highly spatially related in space. Spatial spillover effects are not only caused by the spillover of elements and knowledge, but also spatial competition and learning effects between regions. The regional government often adjusts the policies of the region by learning a certain policy of the neighboring region to achieve economic growth in the region. Allers \& Elhorst (2005) studied the issue of tax competition among local governments from the perspective of spatial spillover. The construction of transportation infrastructure is naturally no exception. Existing literature also studies the promotion of competition between local governments in the construction of transportation infrastructure. Therefore, if we do not consider the 
impact of the construction of the transportation infrastructure in the neighboring areas on the region, it is obviously contrary to economic common sense. In addition, ignoring the spatial lag of the independent variables will theoretically affect the estimated result. Ignoring the relevant explanatory variables in the regression equation will affect the unbiasedness and consistency of the remaining variables. Therefore, after fully considering the actual transportation infrastructure construction and theoretical basis, the addition of the spatial lag of transportation infrastructure can reflect the influence of transportation infrastructure construction on industrial agglomeration in a more comprehensive way. Based on the advantages of the spatial Dubin model, this paper chooses the spatial Dubin model to measure the impact of transportation infrastructure construction on local industrial agglomeration and industrial agglomeration in neighboring areas. The basic form of this model can be set as:

$$
y_{i j}=\delta \sum W_{i j} y_{i j}+\alpha+\beta X_{i j}+\theta \sum W_{i j} X_{i j}+\mu_{i}+\lambda_{j}+\varepsilon_{i j}
$$

Where $\mathrm{Y}$ is the model's explained variable industry agglomeration (lnjymd); $\mathrm{X}$ is an $\mathrm{N} \times \mathrm{K}$ order matrix containing $\mathrm{K}$ control variables, and $\mathrm{X}$ includes transportation infrastructure (lnglmd), local protection (lndfbh), market size (lnrgdp), Human capital (lnrlzb), service industry development (lnfwy), and degree of opening to the outside world (lnfdi); $\beta$ is the parameter vector to be estimated, which can reflect the degree of X's influence on Y. $\varepsilon$ is a random disturbance item that obeys a normal distribution, reflecting the influence of other factors on the explained variable; $\delta$ measures the impact of industrial agglomeration in neighboring areas on local industrial agglomeration; $\theta$ measures the impact of transportation infrastructure in neighboring areas on local industrial agglomeration influences. When $\theta$ is equal to zero, the spatial Durbin model (SDM) model can be simplified to a spatial lag model (SLM), when $\theta+\delta^{*} \beta$ is equal to zero, the spatial Durbin model (SDM) can be transformed into a spatial error model (SEM) .

When Moran's I index is significantly non-zero, it indicates that the spillover of economic activity across regions makes the economic variables examined spatially correlated, thus invalidating traditional panel estimates and requiring the use of spatial measures. As for the specific use of the spatial lag model (SLM), the spatial error model (SEM) or the spatial Dubin model (SDM), estimation tests are required to see whether SDM can be reduced to SLM or SEM.

Table 5. LM inspection results

\begin{tabular}{lll}
\hline test & Statistics & P value \\
\hline LM(lag)test & 6.5840 & 0.0100 \\
Robust LM(lag)test & 0.50200 & 0.4790 \\
LM(error)test & 11.684 & 0.0010 \\
Robust LM(error)test & 5.6020 & 0.0180 \\
\hline
\end{tabular}

According to the test results in Table 5, both LM (lag) test and LM (error) test are significant at the 1\% level, indicating that the data has a spatial spillover effect, and that both SLM and SEM meet the analysis of the data in this paper. Comparing Robust LM (lag) test and Robust LM (error) test, Robust LM (error) test passed the test at the level of 5\%, while Robust LM (lag) test failed the test, indicating that compared to SLM, choose SEM is better. When making a model selection for spatial measurement, it is important to look not only at the LM test results, but also at a combination of the Wald and LR tests, the test results are shown in Table 6.

Table 6. Wald test and LR test results

\begin{tabular}{lll}
\hline test & Statistics & P value \\
\hline Wald_spatial_lag & 27.2800 & 0.0000 \\
Wald_spatial_error & 23.4100 & 0.0000 \\
LR_spatial_lag & 26.7800 & 0.0000 \\
LR_spatial_error & 30.8400 & 0.0000 \\
\hline
\end{tabular}

The results of Wald test and LR test show that Wald_spatial_lag and LR_spatial_lag also reject the null hypothesis that $\theta$ is zero at the $1 \%$ significance level, and Wald_spatial_error and LR_spatial_error also reject $\theta+\delta^{*} \beta$ at the $1 \%$ 
significance level. The null hypothesis is zero. It is more appropriate to use the SDM model in this article.

Because the research sample in this article comes from the panel data of a specific individual, the statistical value of the Hausman test is 77.09, and it is significant at the $1 \%$ statistical level. According to the results of the Hausman test, this article should choose a fixed effects model. Combining the above spatial autocorrelation test and theoretical analysis, and after testing, the situation of the spatial Dubin model is set as follows:

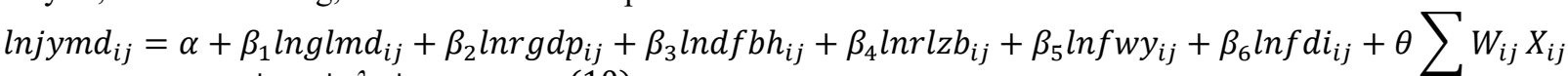

$$
\begin{aligned}
& +\mu_{i}+\lambda_{j}+\varepsilon_{i j}
\end{aligned}
$$

In the existing literature, it is generally believed that areas with closer geographical distances are more closely related and areas farther apart are less connected. In terms of the factors of geographical distance, most of them use adjacent spatial weight matrix and inverse distance matrix. These two spatial weight matrices are relatively intuitive and convenient to calculate. However, it is not only simple economic factors or socio-economic factors that affect spatial spillover effects, but both affect the spatial spillover effects of inter-regional economic activities at the same time. The use of such spatial weight matrices does not provide a good integration of the effects of distance and social factors on spatial spillover effects. This paper uses a nested spatial weight matrix that can comprehensively consider the impact of geography and society on spatial spillover effects, and also lists the regression results of SDM, SAR and SEM, as shown in Table 7.

Table 7. Estimation results of spatial measurement model

\begin{tabular}{|c|c|c|c|}
\hline Variables & SDM & SAR & SEM \\
\hline \multirow{2}{*}{ lnglmd } & $0.0036^{* * *}$ & 0.0001 & 0.0012 \\
\hline & $(-3.00)$ & $(0.18)$ & $(-1.04)$ \\
\hline \multirow{2}{*}{$\ln r g d p$} & -0.0020 & $0.0017^{*}$ & 0.0009 \\
\hline & $(-1.31)$ & (1.69) & $(0.53)$ \\
\hline \multirow{2}{*}{$\operatorname{lnd} d b h$} & -0.0172 & -0.0047 & -0.0112 \\
\hline & $(-1.17)$ & $(-0.33)$ & $(-0.74)$ \\
\hline \multirow{2}{*}{$\operatorname{lnrlzb}$} & $-0.0104^{* * *}$ & $-0.0129^{* * *}$ & $-0.0125^{* * *}$ \\
\hline & $(-2.76)$ & $(-3.39)$ & $(-3.32)$ \\
\hline \multirow{2}{*}{$\ln f w y$} & $0.0045^{* *}$ & $0.0069^{* * *}$ & $0.0076^{* * *}$ \\
\hline & $(2.55)$ & $(4.04)$ & $(3.90)$ \\
\hline \multirow{2}{*}{$\operatorname{lnfdi}$} & $-0.0010^{* * *}$ & $-0.0013^{* * *}$ & $-0.0011^{* * *}$ \\
\hline & $(-3.02)$ & $(-3.91)$ & $(-3.34)$ \\
\hline \multirow{2}{*}{$W^{*} \ln g \operatorname{lm} d$} & $0.0065^{* * *}$ & & \\
\hline & $(3.62)$ & & \\
\hline \multirow{2}{*}{$W^{*} \ln d f b h$} & $0.2609^{* * *}$ & & \\
\hline & $(3.83)$ & & \\
\hline \multirow{2}{*}{$W^{*} \ln f d i$} & $-0.0052^{* * *}$ & & \\
\hline & $(-3.39)$ & & \\
\hline$N$ & 560 & 560 & 560 \\
\hline$r 2$ & 0.3977 & 0.2979 & 0.3863 \\
\hline
\end{tabular}

It can be seen from the above Table that the construction of transportation infrastructure and the development of service industries can promote the development of regional industrial agglomeration, while the increase in human capital and the degree of openness inhibits the level of regional industrial agglomeration. In addition, the spatial lag term is significantly not zero, indicating that the construction and improvement of transportation infrastructure can promote the level of industrial agglomeration in the surrounding areas. Therefore, the use of traditional OLS 
regression will cause the regression results to be biased due to ignoring the spatial effect. Specifically, it seems that transportation infrastructure and local protection have promoted the level of industrial agglomeration in the surrounding areas, while the increase in the degree of opening up to the outside world has inhibited the level of industrial agglomeration in the surrounding areas. From the perspective of R2, the spatial Durbin model (SDM) has a higher degree of fit, and combined with the previous test results, the SDM estimate is used as the basis for the conclusion analysis.

Because the spatial Dubin model (SDM) contains both the spatial lag term of the independent variable and the spatial lag term of the dependent variable, the variable coefficients of the independent variable do not accurately reflect the effect of the independent variable on the dependent variable when estimated using the Spatial Durbin Model. Therefore, referring to the partial differential method of Lesage \& Pace (2009) can well judge whether there is space overflow due to the influence of the independent variable (Table 8).

Table 8. Decomposition of direct effects and indirect effects of spatial Dubin model

\begin{tabular}{lllllll}
\hline variable & Direct effect & \multicolumn{3}{c}{ Indirect effect } & \multicolumn{2}{c}{ Total effect } \\
\cline { 2 - 6 } & coefficient & T value & coefficient & T value & coefficient & T value \\
\hline lnglmd & $-0.0034^{* * *}$ & 0.0012 & $0.0097^{* * *}$ & 0.0033 & $0.0063^{* *}$ & 0.0030 \\
lnrgdp & -0.0021 & 0.0015 & -0.0023 & 0.0019 & -0.0044 & 0.0032 \\
lndfbh & -0.0073 & 0.0138 & $0.5105^{* * *}$ & 0.1320 & $0.5032^{* * *}$ & 0.1327 \\
lnrlzb & $-0.0106^{* * *}$ & 0.0038 & $-0.0113^{* *}$ & 0.0055 & $-0.0219^{* *}$ & 0.0086 \\
lnfwy & $0.0046^{* * *}$ & 0.0017 & $0.0048^{* *}$ & 0.0022 & $0.0094^{* *}$ & 0.0037 \\
lnfdi & $-0.0012^{* * *}$ & 0.0003 & $-0.0116^{* * *}$ & 0.0035 & $-0.0128^{* *}$ & 0.0035 \\
\hline
\end{tabular}

Due to the existence of spatial spillover effects, transportation infrastructure can no longer be individually interpreted as an impact on industrial agglomeration. Therefore, its total spatial effects need to be decomposed into direct effects and indirect effects: direct effects measure local effects, that is, the impact of transportation infrastructure construction on the promotion of local industrial agglomeration; the indirect effect measures the spatial spillover effect, which reflects the impact of transportation infrastructure construction in neighboring areas on the local industrial agglomeration; the total effect measures the total effect on the entire region.

According to Table 8: a). The transportation infrastructure coefficient under the direct effect is -0.0034 , and it is significant at the level of $1 \%$, which means that for every $1 \%$ increase in transportation infrastructure, the local industrial agglomeration will increase by $-0.34 \%$. The effect is negative, indicating that the construction of urban transportation infrastructure in the Yangtze River Delta has a certain inhibitory effect on local industrial agglomeration. b). The transportation infrastructure coefficient under the indirect effect is 0.0097 , which is significant at the $1 \%$ level, indicating that the transportation infrastructure construction of the cities in the Yangtze River Delta is perfect to promote the flow of factors to surrounding cities. And the total effect is positive, indicating that the improvement of the transportation infrastructure in the region has generally promoted the level of industrial agglomeration in various regions. c). From the analysis of the above direct effects, indirect effects and total effects, it can be seen that the impact of transportation infrastructure construction on industrial agglomeration does have a spatial spillover effect, and the spatial spillover effect has a greater impact. If the spatial spillover effect of the transportation infrastructure is not considered, it will Underestimate the role of transportation infrastructure in promoting industrial agglomeration. d). The coefficient of the city scale variable is negative, which verifies the theoretical analysis of the previous article. That is, the central city generally has a relatively high degree of agglomeration, which has produced a certain congestion effect. The larger the city, the more obvious the effect of restraining industrial agglomeration. However, the coefficient is not significant. This may be due to the small sample size selected, which results in a lack of data in the city sample that produces the "congestion effect". At the same time, taking into account the characteristics of the Yangtze River Delta region, some of the peripheral cities that are factor inflow locations are also large in scale, which affects the statistical significance.

\subsection{Robustness Test}

In order to further verify the reliability of the research results in this paper, this paper adopts two methods: 
replacement space weight matrix and replacement regression method to test the robustness.

\subsubsection{Replace the Spatial Weight Matrix}

"The first law of geography" shows that: any two points in space have some connection between them, but the closer two points are more closely connected. The inverse distance matrix can expresses this well, and compared with the nested matrix, the inverse distance matrix has the characteristics of more convenient setting and calculation. Most of the existing literature uses the inverse distance matrix for regression analysis, so this article uses the inverse distance matrix to test robustness. The results are reported in Table 9. It can be seen from the Table that the test results still support the promotion of regional industrial agglomeration and positive spatial spillover effects in this paper. There were also no significant changes in the sign and significance levels of the other control variables.

\subsubsection{Alternative Regression Method}

The least squares method fits the best function match between variables by minimizing the sum of squares of errors, and because of its simplicity and ease of use, it has become one of the most widely used regression methods in the existing literature. This paper uses the least squares method to compare the results with the main regression to verify the robustness of the research.The regression results are reported in the second column of Table 9. It can be found that this paper uses the least squares method to compare the results with the main regression to verify the robustness of the research.the sign and significance of the control variables have changed significantly, but it can still verify the robustness of the transportation infrastructure in this article to promote the level of industrial agglomeration.

Table 9. Robustness test

\begin{tabular}{|c|c|c|}
\hline variable & Replacement space weight matrix & Replacement regression method \\
\hline \multirow{2}{*}{$\operatorname{lnglmd}$} & $0.0033^{* * *}$ & $0.0037^{* * *}$ \\
\hline & $(-2.72)$ & $(3.56)$ \\
\hline \multirow{2}{*}{$\ln r g d p$} & -0.0007 & $0.0040^{* * *}$ \\
\hline & $(-0.46)$ & $(5.12)$ \\
\hline \multirow{2}{*}{ lndfbh } & -0.0139 & $0.1453^{* * *}$ \\
\hline & $(-0.94)$ & $(8.22)$ \\
\hline \multirow{2}{*}{$\operatorname{lnrlzb}$} & $-0.0105^{* * *}$ & $0.0084^{* * *}$ \\
\hline & $(-2.77)$ & $(8.48)$ \\
\hline \multirow{2}{*}{$\ln f w y$} & $0.0054^{* * *}$ & 0.0039 \\
\hline & $(3.11)$ & $(1.39)$ \\
\hline \multirow{2}{*}{$\ln f d i$} & $-0.0010^{* * *}$ & $-0.0018^{* * *}$ \\
\hline & $(-3.04)$ & $(-3.70)$ \\
\hline \multirow{2}{*}{$W^{*} \operatorname{lng} \operatorname{lm} d$} & $0.0054^{* * *}$ & \\
\hline & $(3.15)$ & \\
\hline \multirow{2}{*}{$W^{*} \ln d f b h$} & $0.2247^{* * *}$ & \\
\hline & $(4.10)$ & \\
\hline \multirow{2}{*}{$W^{*} \ln f d i$} & $-0.0037^{* * *}$ & \\
\hline & $(-2.72)$ & \\
\hline \multirow[t]{2}{*}{$N$} & 560 & 560 \\
\hline & 0.3355 & 0.5685 \\
\hline
\end{tabular}

\section{Research Conclusion}

On the basis of combing the existing literature, this paper combines theory and empirical research to study the spatial spillover effects of transportation infrastructure in the Yangtze River Delta region on industrial agglomeration. The 
flow of goods and elements between enterprises makes the forward and backward connections between enterprises have a strong spatial dependence, and the construction of transportation infrastructure can also speed up the circulation of goods and elements. This paper analyzes the influence mechanism of regional industrial agglomeration and industrial diffusion, studies the path of transportation infrastructure to the spatial spillover effect of industrial agglomeration, and proposes that the transportation infrastructure has spatial spillover effects, that is, the construction of local transportation infrastructure can pass forward and backward between enterprises. Contact affects the flow of surrounding products and elements. And starting from China's existing fiscal decentralization and performance appraisal of local officials' selection system, it analyzed the mechanism of spatial spillover effects in the construction of transportation infrastructure in various regions. The competition between regions has prompted various regions to attract more factors by increasing the construction of transportation infrastructure.

Combining the characteristics of the study area, the Yangtze River Delta region, one of the important engines of China's economic development, has attracted a large amount of capital and labor. With the further development of the economy, Individual cities in the region are already experiencing a range of problems due to the congestion effect. At this time, it is of great practical significance to strengthen the construction of transportation infrastructure in the surrounding areas and ease the pressure on the central area. The realization of regional transportation integration is a prerequisite for achieving regional economic integration. To strengthen the economic links between the central area and the peripheral areas, and to promote the free flow of factors to places with high rates of return, it is necessary to reduce the flow cost of products and factors in the peripheral areas. According to the empirical results of the measurement part of this article, the transportation infrastructure construction in the Yangtze River Delta region is indeed in a state of agglomeration development, indicating that various regions have indeed strengthened the supply of transportation infrastructure in the region under the pressure of economic growth.

In terms of empirical research, this paper uses the three spatial weight matrices of proximity matrix, geographic distance matrix and nested matrix to measure the Moran index of the research variables, and verifies the positive spatial spillover of transportation infrastructure construction and industrial agglomeration. The effect shows that the linkages in production make the factors do exist in spatial aggregation, and it verifies the existence of regional competition effects. At the same time, the spatial spillover effects of transportation infrastructure on industrial agglomeration was verified by constructing a spatial Dubin model (SDM). Specific conclusions include:

First, the construction of transportation infrastructure in the Yangtze River Delta is relatively fast, but the construction is uneven among regions. The Moran index of the transportation infrastructure under the three spatial weight matrices is significantly positive, indicating that the high value of the transportation infrastructure in each region is adjacent to the high value, and the low value is adjacent to the low value. It proves that there is a "comparison effect" between regions in the construction of transportation infrastructure caused by competition among local governments, which manifests as a positive spatial spillover effects in space.

Second, the industrial layout of the Yangtze River Delta region presents an obvious "center-periphery" feature. Through data analysis of 40 prefecture-level cities in the Yangtze River Delta region, the global Moran's I index of employment density is significantly positive, that is, the industrial layout of the Yangtze River Delta region presents a concentrated distribution.

Third, the transportation infrastructure has a certain promotion effect on the overall level of regional industrial agglomeration. However, according to the partial differential results of the spatial Dubin model (SDM), the direct effect of the transportation infrastructure is negative, which means that the construction of the transportation infrastructure has produced a certain degree of restraint on the local agglomeration of industries. The partial differential decomposition results of the Spatial Dubin Model (SDM) show that the indirect effects of transportation infrastructure are significantly positive, that is, transportation infrastructure has a positive spatial spillover effect on the flow of factors between regions, that is to say: the construction of local transportation infrastructure drives The clustering of elements in the surrounding area. Due to the existence of spatial spillover effects, this has put forward higher requirements for the Yangtze River Delta region to further coordinate regional coordinated development and reasonable layout planning of transportation infrastructure.

\section{References}

Allers, M. A., \& Elhorst, J. P. (2005). Tax mimicking and yardstick competition among local governments in the Netherlands. International tax and public finance, 12(4), 493-513. https://doi.org/10.1007/s10797-005-1500-x

Anselin, L., \& Bera, A. K. (1998). Introduction to spatial econometrics. Handbook of applied economic statistics, 237. https://doi.org/10.1201/9781420064254 
Aschauer, D. A. (1989). Is public expenditure productive?. Journal of monetary economics, 23(2), 177-200. https://doi.org/10.1016/0304-3932(89)90047-0

Baldellou, F. P., Santolaria, L. F. L., \& Sanz, F. (2002). Evolution of the Spanish Urban Structure during the Twentieth Century. Documentos de trabajo (Universidad de Zaragoza. Facultad de Economía y Empresa), (1), 1. https://doi.org/10.1080/0042098032000053923

Baldwin, R., Forslid, R., Martin, P., Ottaviano, G., \& Robert-Nicoud, F. (2011). Economic geography and public policy. Princeton University Press.

Banister, D., \& Thurstain-Goodwin, M. (2011). Quantification of the non-transport benefits resulting from rail investment. Journal of Transport Geography, 19(2), 212-223. https://doi.org/10.1016/j.jtrangeo.2010.05.001

Crain, W. M., \& Oakley, L. K. (1995). The politics of infrastructure. The Journal of Law and Economics, 38(1), 1-17. https://doi.org/10.1086/467323

Fan, J. Y. (2006). Industrial Agglomeration and Difference of Regional Labor Productivity: Chinese Evidence with International Comparison [J]. Economic Research Journal, 11, 72-81.

Fujita, M., Krugman, P. R., \& Venables, A. (1999). The spatial economy: Cities, regions, and international trade. MIT press.

Goodchild, M. F. (1992). Geographical data modeling. Computers \& Geosciences, 18(4), 401-408. https://doi.org/10.1016/0098-3004(92)90069-4

Huang, J. L., \& Li, K. W. (20069+559*). Foreign trade, local protection and China's industrial layout. Economics (Quarterly), 2006(02), 733-760.

Jin, S., \& Tokunaga, C. (2010). Market potential, proximity of raw materials and location selection of Japanese food industry investment in China. Economic Geography, 30(6), 976-981.

Liu, J. Q., \& Zhao, Y. L. (2010). Transportation infrastructure, market acquisition and manufacturing location: empirical data from China. Nankai Economic Research, 2010(04), 123-138.

Liu, Y. P., \& Wen, Y. Y. (2015). The influence of labor pool effect and knowledge spillover effect on labor income share--Based on Marshall's theory of industrial agglomeration. Journal of Yunnan University of Finance and Economics, 31(6), 3-12.

Ozbay, K., Ozmen-Ertekin, D., \& Berechman, J. (2007). Contribution of transportation investments to county output. Transport Policy, 14(4), 317-329. https://doi.org/10.1016/j.tranpol.2007.03.004

Rauch, J. E. (1994). Bureaucracy, infrastructure, and economic growth: evidence from US cities during the progressive era (No. w4973). National Bureau of Economic Research. https://doi.org/10.3386/w4973

Shen, H., \& Xiang, X. Y. (2017). Specialization, related diversification and enterprise cost plus-a new perspective to test the externalities of industrial agglomeration. Economic Trends, 2017(10), 81-98.

Shi, D. W., \& He, Y. F. (2011). Industrial specialization, industrial diversification and urban economic growth. China Urban Economy, 2011(2), 36-37.

Shirley, C., \& Winston, C. (2004). Firm inventory behavior and the returns from highway infrastructure investments. Journal of Urban Economics, 55(2), 398-415. https://doi.org/10.1016/j.jue.2003.11.001

Tobler, W. R. (1979). Lattice tuning. Geographical Analysis, 11(1), 36-44. https://doi.org/10.1111/j.1538-4632.1979.tb00671.x

Young, A. (2000). The razor's edge: Distortions and incremental reform in the People's Republic of China. The Quarterly Journal of Economics, 115(4), 1091-1135. https://doi.org/10.1162/003355300555024

Zhang, K., \& Wang, D. F. (2014). The interaction and spatial spillover of economic agglomeration and environmental pollution. China Industrial Economics, 2014(6), 70-82.

Zhang, X. L. (2012). Does China's transportation infrastructure promote regional economic growth. Concurrently on the Spatial Spillover Effect of Transportation Infrastructure. Chinese Social Sciences, (3), 60-77.

Zhou, L. A. (2004). Incentives and Cooperation of Government Officials in the Promotion Game-Also on the Long-Term Reasons of Local Protectionism and Repetitive Construction in China. Economic Research, (6), $33-40$.

Zhou, Y. H., Zong, Q. Q., \& Chen, X. (2003). The scale competition of prefecture level government education 
expenditure under the fiscal decentralization system. Economic Research, 48(11), 127-139+160.

\section{Notes}

Note 1. Data comes from the National Bureau of Statistics of China.

\section{Copyrights}

Copyright for this article is retained by the author(s), with first publication rights granted to the journal.

This is an open-access article distributed under the terms and conditions of the Creative Commons Attribution license (http://creativecommons.org/licenses/by/4.0/). 